\title{
CORPUS Corpus
}

Archivos virtuales de la alteridad americana

Vol 1, No 2 | 2011

Julio / Diciembre 2011

\section{Relaciones interétnicas y prácticas de atención de la salud en el Chaco Salteño}

Interethnic relations and practices of health care in the region Chaco Salteño

\section{Mariana Lorenzetti}

\section{(2) OpenEdition}

Journals

Electronic version

URL: http://journals.openedition.org/corpusarchivos/1150

DOI: 10.4000/corpusarchivos. 1150

ISSN: 1853-8037

\section{Publisher}

Diego Escolar

\section{Electronic reference}

Mariana Lorenzetti, « Relaciones interétnicas y prácticas de atención de la salud en el Chaco Salteño », Corpus [En línea], Vol 1, No 2 | 2011, Publicado el 30 diciembre 2011, consultado el 01 mayo 2019. URL : http://journals.openedition.org/corpusarchivos/1150; DOI : 10.4000/corpusarchivos. 1150

This text was automatically generated on 1 May 2019. 


\section{Relaciones interétnicas y prácticas de atención de la salud en el Chaco Salteño}

Interethnic relations and practices of health care in the region Chaco Salteño

Mariana Lorenzetti

\section{EDITOR'S NOTE}

Fecha de recepción del original: 29/08/2011

Fecha de aceptación para publicación: 06/10/2011

\section{Introducción}

1 En los últimos años, se advierte desde las agencias estatales argentinas una creciente preocupación por la "salud indígena" centrada fundamentalmente en discutir el acceso y el alcance de la atención médica y programas sanitarios a dicho sector poblacional. En este marco, distintas iniciativas del Ministerio de Salud de la Nación fueron configurando un conjunto de directrices que fijaron, como objetivo prioritario, promover una "adecuación cultural" en las intervenciones socio-sanitarias. Todo ello dirigido a reducir las brechas de los indicadores de salud desfavorables entre la población indígena y no indígena. ${ }^{1}$

2 De este modo, la necesidad de formular programas específicos fue delimitando qué es posible -y qué no- pensar, decir y hacer respecto de la promoción de la salud de la población indígena, incorporando el tópico de la "interculturalidad" como clave de gestión. En tanto espacio emergente, dentro de la agenda pública, el dominio de la "salud intercultural" ha implicado un re-ordenamiento de las diferencias decodificándolas en términos "culturales". 
3 Si bien diversos trabajos abordaron las experiencias de "salud intercultural" en distintos contextos locales y nacionales (Albó 2004; Arrue y Kalinsky 1991; Boccara 2004; Boccara y Bolados 2008; Cuyul 2008; Fernández Juárez 2006; Ramírez Hita 2009), han sido pocos los estudios que, más que centrarse en la formulación y la implementación en función de establecer el grado de correspondencia entre una y otra instancia, problematizaron los usos sociales del término "intercultural" y desnaturalizaron los sentidos comunes asociados al mismo (Briones 2005; Boccara 2007; García Vázquez 2009; Menéndez 2001; Tamagno 2009).

En esta dirección, el trabajo analiza qué implica la traducción e incorporación de lo que se recorta y califica como "cultural" en el ámbito sanitario local del Chaco Salteño, específicamente en el departamento de San Martín. ${ }^{3}$ Me interesa puntualmente examinar cómo las condiciones de salud de la población indígena han cobrado visibilidad en el ámbito sanitario-asistencial local. Partiendo de que la salud no es una entidad abstracta, ni algo dado, sino una "producción social" (Fassin 2004) me centraré en la manera en que hegemónicamente, desde la mirada criolla, se concibe a la población indígena del Chaco Salteño y se da una expresión sanitaria a ciertos problemas sociales.

Dentro de estas coordenadas de análisis, cabe entender la "producción de la salud" como forma de instituir un ordenamiento social donde distintos agentes sociales, con desigual capacidad de decisión y acción social, participan definiendo cómo y qué cuestiones conciernen al ámbito de la salud. Por medio de este proceso los sujetos involucrados van recreando sentidos de percepción y apreciación de las dimensiones constituyentes de la trama social, siendo esos sentidos inseparables de las prácticas que se instituyen en nombre de la salud.

En primer lugar, entonces, explicito los aspectos relevantes del contexto socio-político del Chaco Salteño que sirven de encuadre de las intervenciones sanitarias. Re-conociendo que éstas no operan en un vacío -sino que se encuentran condicionadas por una matriz de alteridad histórica y por cierta configuración social (Briones 2005; Segato 2007)- analizo los factores condicionantes de las prácticas de los efectores de la salud pública -esto es: agentes sanitarios, médicos, personal administrativo- $\mathrm{y}$ de los indígenas asistidos dentro del sistema de salud. En segundo lugar, el núcleo de indagación está centrado en reconstruir algunas experiencias relativas al acceso a la atención médica de las comunidades indígenas peri-urbanas de la localidad cabecera del departamento.

7 Sólo teniendo presente el carácter de la configuración de las relaciones entre los criollos/ blancos y los indígenas -que estructuran localmente las interacciones y vínculos interétnicos- es posible hacer inteligible cómo y qué se pondera en términos culturales. Ello nos permitirá sopesar cómo es decodificada la necesidad de realizar una "adecuación cultural" de los servicios de atención y qué implican, en términos prácticos, tales procedimientos.

\section{La configuración de las relaciones interétnicas en el Chaco Salteño}

8 Como ya adelanté, prestar atención a la configuración de determinados sentidos sedimentados de las diferencias étnicas-culturales en el Chaco Salteño constituye una tarea imprescindible; en la medida en que los usos de dichas construcciones sociales son las que sirven de encuadres de interpretación y justificación de las intervenciones socio- 
sanitarias (Menéndez 2001). Particularmente pretendo aquí dar cuenta de cómo ciertas prácticas de diferenciación, efectuadas por los criollos, van marcando a los indígenas del Chaco Salteño como distintos/desviantes, erigiendo lo que se define propiamente "criollo" como aquello que designa y distribuye valor.

9 Atendiendo a los imaginarios sociales -recortados sobre una narrativa oficial- puede entenderse cómo esas líneas divisorias entre criollos y aborígenes, por cierto porosas, son puestas en acto e inscriptas en una memoria presente al momento de explicar el carácter del vínculo entre unos y otros. En dichos imaginarios sociales, lugares, tiempos y relaciones sociales se conjugan de manera singular, expresándose en la conformación de un espacio que ha sido y es efecto de procesos político-económicos resultantes de fuerzas históricas (Gordillo 2006).

Producto de una combinación de influencias socioculturales e históricas, dichos imaginarios son actualizados en situaciones concretas y nos advierten tanto de la construcción de un pasado como de la forma de entender un presente. Es en este marco que puede explicarse el relato que me hiciera una enfermera sobre un "antes" y un "ahora" de las relaciones indígenas-criollos, a propósito de referirse a la aceptación de las intervenciones socio-sanitarias por parte de las comunidades. A través del mismo, puede rastrearse la inscripción de sentidos hegemónicos que distintos procesos fueron dejando en las experiencias constitutivas de lo que son las relaciones criollos-indígenas. ${ }^{4} \mathrm{Me}$ interesa reparar en él, en tanto no sólo condensa la manera en que muchos criollos explican la situación de los indígenas, sino también justifican sus formas y necesidad de intervenir. La evocación de determinados hitos en dicho relato remite tanto al lugar y posición social de quién habla, como también al modo en que éstos configuraron y van moldeando el carácter de las relaciones interétnicas. En dicha oportunidad, autodefinida como una "criolla chaqueña" y conocedora de los indígenas, la enfermera comenzaba a describir la relación entre criollos e indígenas de la siguiente manera:

Yo conozco bien a los aborígenes, prácticamente me he criado con ellos. Uno de mis abuelos fue uno de los primeros expedicionarios en llegar al Chaco [Pilcomayo]. Fue con Astrada. ${ }^{5}$ En ese entonces, mi abuelo ha contado, que cuando el indio veía gente se escondía, se disparaba. Ahora no, ya se dejan vacunar, ha cambiado mucho la cosa. Como dicen se han civilizado, ya están amansados. Antes se mataban entre ellos los aborígenes. No era que los criollos mataban a los aborígenes. Estaban en conflicto entre ellos. Se peleaban con los chorotes, porque los chorotes no son de acá. Son de Bolivia. Los que eran de nosotros son los matacos [wichi]. Yo tengo un mapa donde se divide el Pilcomayo y ahí dice los Chorote de la banda...y los matacos estaban bien hacia acá, hacia la costa de nosotros. (...) A ellos, los viejos que han venido los agruparon, los civilizaron, como se dice los amansaron. Ellos han venido con la meta de civilizarlos, no matarlos a ninguno. Y así como los han civilizado, el gobierno les donó tierras a los expedicionarios. Para ese entonces ellos tenían muchos animales, ellos trabajaban duro. El Astrada era un buen tipo, era ingeniero, era escritor, era de todo. Él era el cabecilla, el que llevaba la tropa adelante. Eso era por 1902, pero se empezó de mucho más antes (...) ya se había avanzado. Desde entonces nosotros ya tenemos las Misiones. Mi abuelo puso a trabajar a los aborígenes, él los alimentaba. Mi abuelo era muy rico... tenía una casa muy grande, de material. Él ha hecho la casa de material cuando todo costaba, antes todo era monte. Ahora tenés caminos (...). Ellos [los criollos] han civilizado a los indígenas. (...) Así que de esa manera están las Misiones.

De manera significativa, la situación de los indígenas es inscripta en este relato recreando algunas de las coordenadas de los procesos que han ido configurando el espacio social del Chaco Salteño. Me interesa señalar al respecto cómo a través del mismo la enfermera va 
en-lazando momentos entre un "antes" y un "ahora" que, al evocarlos conjuntamente, ponen en juego imágenes que ligan al Chaco Salteño como lugar "difícil", de "sacrificio". Un lugar donde la "presencia humana" se vincula a la llegada de "los criollos", cuya meta nada más ni nada menos era/es "civilizar al aborigen" -meta que, equiparada a "amansar", evoca la idea de lo "salvaje", "cuasi-natural" asociado a lo indígena. El calificativo de "gente" es reconocido sólo para el criollo, y negado para el aborigen. El avance del criollo se aprecia como garantía de pacificación en una zona donde "los aborígenes se mataban entre ellos". Asimismo, signos de extranjería se van depositando entre distintos colectivos, con grados de mayor o menor inclusión, reforzando con ello la imagen del criollo como epítome del "ser nacional".

Es dentro de estas coordenadas de sentido que puede hacerse inteligible la denominación en términos de "misiones" con la que, quienes trabajan en el sistema de salud, hacen referencia a las comunidades indígenas. ${ }^{6}$ Con dicho vocablo, se evoca la idea de lugar donde se debe "ir a enseñar", "a predicar", en este caso lo que se define como "cuidados de salud". 7 En consonancia, la aceptación por parte de los indígenas de las intervenciones del sistema de salud implica para los que trabajan allí, un indicio o grado de su predisposición a civilizarse, a progresar. En este sentido, las continuas remisiones entre un "antes" y un "ahora", entre "criollos" y "aborígenes", "progreso" y "atraso", "cambio" $\mathrm{y}$ "costumbre" forman parte de un entramado que explica la textura de las complejas relaciones interétnicas en el campo de la salud.

Como me señalaba la misma enfermera, respecto al trato con el aborigen:

... Me tocó trabajar en todas las misiones... Ahora es otra cosa, ahora es más fácil. Antes eran duros, eran malos. Te rodeaban así al enfermo y no te dejaban. Había que ir a hablarles, repetirles muchas veces, una y otra vez... Ellos miraban nomás. No se dejaban vacunar, veían al agente sanitario y se disparaban nomás. Había que buscar la forma de pillarlos... Ahora algunos están un poco más civilizados, van entendiendo. Antes a la leche no le daban bolilla, ahora sí le dan más leche, la mamadera a los chicos. Pero si te des-cuidas, a ellos le das el paquete de leche y lo van a vender por otra cosa, no son de fiar (...) Todavía hay zonas más adentro que están a las buenas de dios... a mí me dan pena, porque son gente igual que nosotros y sufren tanto...

14 Es interesante reparar cómo en dicho relato el agente sanitario aparece equiparado a la figura del expedicionario. Al igual que entonces, a su llegada los indígenas "se disparaban"; aún hay que buscar la forma de "pillarlos" y "van entendiendo", aunque no se puede "confiar" demasiado en ellos. El accionar del agente sanitario es recalcado en su carácter benévolo y humanitario, destinado a "sacarlos" de un estado de "deriva".

La experiencia de la enfermera va estableciendo relaciones de sentido, también compartidas por otros profesionales, cuando por ejemplo para éstos el "grado de acatamiento" de los "consejos de salud" o de "seguimiento" de las prescripciones médicas de la población indígena se convierte en un indicador a través del cual es posible "medir" cuán indígena se es, en función de ciertos parámetros que son caracterizados como "civilizados". Así, "lo indígena" es atributo de quién "no entiende", de quién no es de "confianza" y de aquello que "hace falta promover" y "cambiar".

No obstante, el Chaco Salteño aparece connotado como un espacio de cambios. A la par de reconocer al indígena ahora "más civilizado" porque "está menos duro" y "acepta" las intervenciones de los criollos (entre otras cosas, hasta deja "vacunarse"), ciertos reclamos o demandas provenientes de las comunidades se convierten en intolerables o directamente inaceptables. En este sentido, la enfermera me señalaba: 
(...) Pero ahora que están más civilizados, están más malos. Están en contra de nosotros. Han cambiado tanto... Yo me acuerdo mi mamá se iba por ahí y nos dejaba en manos de ellos, para que nos cuidaran. Ellos venían a la casa y eran como sobrinos o nietos. Mi mamá adoraba a los aborígenes, vivía rodeada de aborígenes. Ella a la mañana, en una olla grande, ya ponía agua a calentar para el mate cocido. Y ella tenía el afán de hacer pan en el horno de barro, y así les daba un pedazo de pan a cada uno y una taza de mate cocido. Y los mandaba a trabajar, para sembrar. Ahora no, son flojos. Ya no hacen nada, ya se dedican a otra cosa. Ahora todos se han vuelto flojos. (...) Ahora les hacen creer a los aborígenes que son los únicos dueños de la tierra. (...) Hay muchas organizaciones, está la Fundapaz, la Asociana. Uy, un montón hay. A mí me da bronca, porque digo: 'si ellos vienen a velar por ellos, por qué no los ayudan...si tanto le meten en la mente que todo es de ellos, porque no lo ayudan, que los ayuden... Cada día tienen menos y los que menos le ayudan son ellos'. Ellos están cada vez peor. Y dónde están todas las organizaciones. Todas están con sus camionetas 4 x 4, lo único que le ayudan es diciendo: 'la tierra es de ustedes, no dejen entrar a criollos, pero no es tan así'. (...) Yo les digo a los aborígenes 'todos nacimos acá. Nosotros toda la vida hemos vivido con ustedes, ¿qué daño le hicimos a ustedes? '. Ellos se dan cuenta que no tienen dónde ir, porque todo está con alambre...pero yo les digo: ustedes lloran sobre la leche derramada. (...) Los aborígenes dicen que quieren cazar, qué van a cazar, si ya no queda monte. Se ha desmontado todo, ya no quedan animalitos, ya no queda nada (...)".

17 De esta perspectiva, lejos de estimarlos con iniciativas propias, los indígenas aparecen custodiados por un "universo de organizaciones" y con demandas que otros "les meten en la cabeza".

18 En este contexto, las "misiones" indígenas devienen un espacio donde distintos actores intervienen. Actores que van re-configurando las relaciones indígenas-criollos dentro de un escenario conflictivo, tanto por la ocupación de espacios, como por la apropiación de recursos. El conflicto emerge entonces configurado por todo aquello que es percibido como signo desestabilizante de la supeditación del indígena a lo criollo. ${ }^{8}$

Dentro de estas coordenadas el Chaco Salteño, particularmente el departamento de San Martín, emerge como espacio susceptible a ser "colonizado" cada vez que nuevos "frentes de desarrollo" pretenden sacar del "atraso" a una región signada, según los promotores del mismo, por "el olvido" y el "abandono". De este modo, valorizada por una nueva cruzada -esta vez emprendida por corporaciones petroleras, por empresas agroindustriales, y madereras- la región también aparece como "próspera" y "pujante". Así el "avance" de la frontera agropecuaria y la "incursión" de prospecciones y excavaciones en busca de hidrocarburos, junto con la tala de árboles, van, por un lado, forjando la imagen de una región "rica" y "biodiversa". Por el otro, delineando una imagen de "precariedad" e "inestabilidad", la zona queda ligada -tal como me fuera expresado por diferentes profesionales de salud- a una "pobreza endémica, difícil de erradicar". 9

En el caso del Dpto. de San Martín la transformación de este espacio ha dado lugar a una reconfiguración de la movilidad poblacional y control territorial, implicando un reacomodamiento de las relaciones criollos-indígenas. Estos cambios fueron re-calibrando los vínculos entre criollos e indígenas, en función de la nueva valorización tanto del espacio como de una población que ya no es incorporada masivamente a las actividades productivas de la zona. En términos generales y en este marco se advierte una pauperización generalizada que afecta tanto a criollos como a indígenas. Para las comunidades indígenas, tales cambios han implicado una mayor dependencia de un 
espacio constreñido y degradado (el monte), imponiéndoles más necesidad de articular estrategias de subsistencia que van desde usufructuar los recursos que quedan del monte hasta tomar trabajos temporarios, como las changas o realizar el trabajo estacionario en las fincas -denominado poroteada-, combinados con actividades relacionadas a las artesanías o carpintería, como también con la inscripción en planes de trabajo o sociales diversos, tales como el Programa de Empleo Comunitario (PEC), las pensiones, el Programa Familia, entre otros. ${ }^{10}$

Desde la perspectiva criolla hegemónica, la población indígena suele ser interpelada como signo de otro tiempo, "obstáculo del desarrollo y progreso", habitando "un espacio productivo que no trabajan", "tierras que no usan", "que están desaprovechadas", un espacio que sí es vivido y ocupado por indígenas se lo ve y considera de esta forma "improductivo". ${ }^{11}$

Del lado de las comunidades, la "cercanía con los criollos" es vista como elemento disruptivo, expresándose dichas tensiones de diversas maneras. En cierta oportunidad, durante el trabajo de campo, conversando sobre cómo era "antes" y "ahora" la vida en las comunidades, uno de los hombres de una familia wichí expresaba: "antes no se conocía enfermedad, estábamos sanos. No se enfermaba, el paisano andaba nomás". La enfermedad o el deterioro de las condiciones de vida son remitidas al contacto o presencia criolla y su continua expansión sobre los espacios ocupados por las comunidades indígenas. Respecto de las comunidades peri-urbanas, el progresivo arrinconamiento a espacios cada vez más reducidos, la circunscripción a ámbitos cada vez más acotados para su desarrollo y el acrecentamiento de las familias, hacen que algunas de ellas busquen nuevos lugares, a menudo, más deteriorados o de condiciones poco favorables.

De este modo, el "contacto" y/o "proximidad" indígena-criollo se vuelven críticos tanto para unos como para otros. Mientras las comunidades remiten las condiciones de salud deterioradas a la presencia y accionar criollo e identifican la enfermedad al contacto con "lo criollo"; los criollos suelen hacer alusión de "lo aborigen" como aquello que significa obstáculo para "el progreso" y "el avance". En esta configuración, las comunidades devienen en "huéspedes anacrónicos" que obturan el desarrollo productivo y próspero de la región, convirtiéndose en un factor disruptivo siempre latente: esta situación se efectiviza cuando los aborígenes no se supeditan al carisma grupal distintivo del criollo (Elias 2000).

En este sentido, la cuestión indígena vuelve a circular en un campo semántico-social que la configura como signo de otro tiempo, en un presente atravesado por la dinámica de "nuevos frentes productivos". ${ }^{12}$ Dotados de un aura "modernizante" y como sectores "pujantes", tales frentes imprimen una visibilidad particular a la "presencia indígena", inmersa dentro de un espacio ahora valorado y convertido en foco de inversiones.

Dentro de este marco -en los últimos años- las condiciones de salud de la población indígena del departamento de San Martín, han sido interpretadas preponderantemente, desde el ámbito político, sanitario y asistencial, como un "problema de índole cultural". Un claro ejemplo de esta manera de interpretar las condiciones de salud puede verse en el tratamiento que distintos funcionarios del gobierno salteño dieron a los casos de muerte infantil por desnutrición ocurridos en este verano (2011). En dicha oportunidad y frente al estado público de los casos el gobernador afirmaba en diferentes medios que: 
Las muertes de niños en el norte de nuestra provincia de Salta, son un problema cultural, no sanitario ni social, por-que los aborígenes no concurren al hospital" (Radio salta. com 2011).

[A]ún teniendo infraestructura sanitaria no quieren asistir a los hospitales por una cuestión cultural" (La Política On-line 2011). constituyen parte de las argumentaciones con las que frecuentemente se problematiza el acceso al sistema sanitario y se discute el alcance de políticas y programas sociales destinados a la población indígena. Recurrentemente la apelación a las "barreras culturales" como recurso explicativo encuentra encarnadura en diferentes casos, de modo que se convierte en un latiguillo toda vez que, desde el sistema de salud formal, se debe responder sobre las condiciones de salud desfavorables que afectan a la población indígena. Pensadas sólo como un asunto de "atención médica" y aprehendidas bajo el ángulo de las diferencias culturales, tales formas de problematizar la cuestión dejan ensombrecidos los determinantes que están incidiendo en la vida de las comunidades indígenas. Así, a la reducción explicativa del estado de salud indígena como una cuestión de inconmensurabilidad de índole "comunicativa" entre médico y paciente le es concomitante la construcción esencialista de la cultura.

En términos generales, el acceso y alcance de los servicios de salud se tornan materia discutible apelando básicamente a la "adecuación cultural" de las formas de intervención, quedando en un plano secundario el contexto socio-situacional en el que las mismas se desarrollan. Así, como abordaré en el próximo apartado, la atribución de responsabilidades en torno al uso de las prestaciones del sistema de salud formal termina recayendo en la misma población indígena.

Teniendo presente estas consideraciones, me propongo ahora analizar qué implica la "adecuación cultural" de los circuitos de atención en salud dirigidos a la población indígena. A través del análisis de los itinerarios indígenas para ser atendidos, busco dar cuenta de cómo los procedimientos destinados a vehiculizar la atención médica implican una forma de recepción y moldeamiento de las demandas de las comunidades indígenas que construye espacios públicos excluyentes. Con ello apunto a señalar las maneras en que ciertos dispositivos (Deleuze 1999; Foucault 1985) ponen en acto y expresan la construcción de perfiles de usuarios diferenciados, en la medida en que suponen determinadas prácticas orientadas a "facilitar" la accesibilidad de la población indígena al sistema de salud formal.

\section{La atención en el sistema de salud formal: circuitos e itinerarios de la población indígena}

Uno de los problemas que persistentemente visualizan los diferentes profesionales y quienes trabajan en tareas administrativas en el hospital en relación a las desfavorables condiciones de salud de las comunidades, está ligado a la inaccesibilidad de la atención médica atribuida a "barreras culturales" que aquellos proyectan sobre los indígenas. En numerosas oportunidades, durante las conversaciones mantenidas con recepcionistas, médicos y enfermeras, la cuestión de la inaccesibilidad aparecía expresada en frases tales como: "no se saben comunicar", "no pueden contar lo que les pasa", "algunos no hablan, ni entienden el castellano", "son cerrados", "manejan otros tiempos", "ellos se automarginan". 
30 La falta de recursos materiales y humanos para hacer frente a las interminables colas, la escasa disponibilidad de turnos en relación a la demanda, el limitado tiempo de atención para cada paciente, el pedido de la "contribución voluntaria" a personas de escasos recursos, pocas veces son referenciadas como limitantes de la capacidad del hospital para atender demandas. Antes que poner énfasis en estos últimos factores, lo que estas circunstancias propician habitualmente es una descarga de responsabilidades que recae en quienes pretenden acceder a los servicios del hospital, señalándose como único obstáculo al acceso el hecho de carecer de comportamientos adecuados. Así, según los diferentes agentes de salud, quien no consigue turno es porque "no se levanta lo suficientemente temprano" para conseguirlo, porque "no trae la documentación" requerida o porque no es expeditivo en la expresión de sus necesidades.

31 En este marco, toda una batería de mecanismos son los que regulan el modo de acceso a los distintos servicios del hospital y asimismo moldean el tipo de demanda susceptible de ser recepcionada. En el caso que nos ocupa, ellos implican ciertas reglas de juego vinculadas con una dinámica de funcionamiento. Dichas reglas están ligadas a las condiciones para solicitar los turnos médicos de atención y a los canales administrativos para la realización de trámites (autorizaciones para los exámenes clínicos, pago de aranceles como "contribución voluntaria"). Es dentro de las coordenadas recién mencionadas que las demandas provenientes de las comunidades indígenas constituyen un elemento perturbador para los diferentes servicios del hospital. En principio, no sólo porque se espera que ellas sean resueltas por los Centros de Atención Primaria de la Salud (CAPS) a través de los llamados "periféricos" -es decir, a través de los "consultorios extramuros"- sino porque, fundamentalmente, ponen en evidencia la crisis de funcionamiento del sistema de salud local. Así, el acercamiento del indígena al hospital se interpreta como un distorsionamiento o fracaso de los canales de atención previstos para ellos. Lo que se espera es que la figura del agente sanitario, ${ }^{13}$ junto con los dispensarios locales, sean quienes aligeren las tareas al hospital, evitando su saturación, o circunscribiendo en todo caso la intervención del mismo a "casos extremos". Es decir, el hospital es la última instancia y la relación de la población indígena con el hospital aparece mediada por el agente sanitario. Las "derivaciones" que él realiza -donde se establecen los motivos de la necesidad de la atención médica- es el mecanismo a través del cual se va concretando el circuito de atención establecido. Poder contar con "la derivación" es un primer paso para obtener el turno de una forma más "rápida". Pero a veces tener una derivación no es garantía de poder tener éxito en su consecución. En una ocasión cuando acompañaba a una doctora de uno de los CAPS, en su recorrido por "la misión", escuché a una mujer que se quejaba: "doctora, ni al papelito han respetado", señalando el "cansancio" de haber ido al hospital y una vez más no haber conseguido el turno. Aquella frase me quedó grabada, pues no sólo hablaba de un "respeto por un papel", sino que desnudaba cómo asimismo el "valor de un papel revestido de autoridad" podía sin embargo quedar sin efecto. Aun así, la mayoría de las mujeres indican que no es lo mismo ir sin derivación que tener entre sus manos "el papelito" como habitualmente llaman a las derivaciones. Dentro de este marco, entonces, las derivaciones constituyen para los indígenas una forma de "acreditar" la necesidad de atención hospitalaria y, para el agente sanitario, un "comprobante" de haber realizado su trabajo. Así, las derivaciones realizadas por los agentes sanitarios se enmarcan con criterios de regulación de la demanda, hallándose al mismo tiempo, vinculadas al establecimiento de lo que se considera el "buen desempeño". ${ }^{14}$ 

Tal circunstancia relacionada al modo de "apropiación del centro" que se les proponía a las personas de las comunidades próximas, fue la que me llevó a detenerme en esta cuestión. Precisamente comencé a pensar si el acercamiento e involucramiento planteado sólo en términos de mantener limpio el centro sería una de las razones por las cuales mujeres y hombres guardaban cierta distancia como un intento de sustraerse de las imputaciones que, frecuentemente, se les hace respecto al cuidado de la higiene marcándoles de manera reiterada una actitud de descuido o dejadez.

Hombres y mujeres de distintas comunidades -sobre todo tratándose de wichís o chorotes- suelen expresar ambivalentemente la importancia de tener o contar con una derivación o con un agente sanitario criollo que facilite la realización de trámites. De este modo los aborígenes experimentan tales situaciones como una manifestación más de su supeditación a alguien que puede hacer algo que, por sus propios medios o sin su ayuda, les es difícil alcanzar. Pues en definitiva, como me expresaba una anciana, "es la orden del sanitario (la que) tiene valor", y en consecuencia para hacerse acreedor de la atención médica es preciso contar con alguna.

demandas indígenas en relación a la salud y a la atención médica del sistema formal. Estas cuestiones, si bien están vinculadas, desde la perspectiva indígena no se reducen la una a la otra, como preponderantemente suele hacerse desde la óptica de los programas de salud.

grupos familiares aborígenes, el hospital o los CAPS fueron puestos en duda como lugares de sanación/curación. No obstante, dichas referencias no implicaban una negativa total a verlos como posibilidades o alternativas a donde recurrir. En este sentido, lo que frecuentemente aparece cuestionado es que tales espacios se juzgan pertinentes sólo para la sanación/curación de los criollos y denegados, de diversas maneras, para los indígenas. Fueron estas apreciaciones las que me llevaron a indagar sobre las actitudes de rechazo o resistencia que habitualmente en el ámbito local se atribuyen al aborigen respecto a la atención médica y su relación con el sistema de salud formal.

Cuando en una oportunidad acompañé a la coordinadora de Atención Primaria de Salud (APS) a uno de los Centros de Salud, presencié una conversación entre ella y una doctora acerca de la relación de las misiones wichí circundantes con el CAPS. Ante la observación de la coordinadora sobre lo descuidado que se veía el centro de salud y la necesidad de mantenerlo limpio, la doctora le comentaba la indiferencia que la gente del lugar parecía tener con el CAPS puesto que, habiendo convocado a algunas de las mujeres para limpiar y así conservar el CAPS, ninguna se había acercado, lo cual era interpretado como falta de interés en relación a dicho espacio; un espacio que por tener un emplazamiento en ese lugar deberían considerarlo de ellos -el CAPS está ubicado a menos de 10 kilómetros del hospital y en un espacio intercomunitario donde se concentran varias "misiones"-.

A través de tales comentarios, las profesionales buscaban remarcarme cómo, a pesar de estar dentro del ámbito comunitario, la gente era reacia a acercarse al Centro de Salud. No obstante, más tarde, a raíz del contacto con una de las agentes sanitarias a cargo de dicho sector de trabajo, la cuestión del acercamiento y la relación con el CAPS de las comunidades próximas mostrarían otras aristas. Conversando con ella sobre si, al existir un CAPS próximo, le resultaba más fácil derivar, me explicaba que no necesariamente disponer de atención médica "más cerca" aliviana el acceso, pues: 
"La gente de acá es muy conflictiva. Los médicos no duran mucho, no quieren venir a trabajar acá [al CAPS], por esto que te digo que son muy problemáticos. Enseguida levan-tan notas, hacen notas y los terminan botando [echando]. Bueno, ningún médico que ha estudiado años y años va a querer venir a trabajar acá para que se lo maltrate". acompañamiento supone una tergiversación de los canales de atención previstos para ellos. La atención en el hospital del indígena tiene un grado de receptividad mayor en la medida en que las derivaciones acreditan la necesidad de atención hospitalaria, actuando además muchas veces como "traductora" de la demanda, en tanto que allí el agente consigna las razones y síntomas que ameritan la consulta médica. A diferencia de otros usuarios del sistema, para el indígena la capacidad de ser recepcionado o escuchado en el hospital sólo es posible en la medida que pueda conseguir a alguien quien lo "represente" en el servicio de atención.

En este sentido, los dispositivos como las "derivaciones", o la designación de "referentes comunitarios" encargados de "agilizar" la atención de las demandas indígenas en los 
distintos servicios de salud del hospital, constituyen formas que coadyuvan a la interiorización de las reglas de juego. Ellos implican una idea de "minoridad indígena" y una burocratización del acceso a la salud pública que hacen necesaria la figura de un "traductor" capaz de establecer el enlace con el hospital, trayendo consecuentemente aparejada la extensión del control y el afianzamiento del poder de los profesionales sobre las demandas indígenas.

En efecto, ese "acto de reconocimiento" a través de terceros, pauta un régimen de visibilidad demostrativo del itinerario del indígena para acceder al hospital, quien aparece en escena acompañado, siendo ese acompañamiento ambiguamente connotado, tanto señal de consideración como signo de estigmatización. En este sentido, más que constituirse en "la puerta de entrada", tal mecanismo parece cristalizar el tope del derecho de asistencia médica para las comunidades indígenas.

Se trata pues de un "derecho a la asistencia" fundado en una "ciudadanía biológica" (Concepto de Petryna, como se cita en Fassin, 2008), en tanto las personas precarizadas encuentran únicamente "un lugar" a partir de un cuerpo que padece, donde son los trastornos "físicos" visibles y el lenguaje del padecimiento los que movilizan las acciones desde la salud pública hacia la población indígena (Fassin 2008). Son estos circuitos ligados a la necesidad de contar con una derivación o algún contacto con el agente sanitario u otro profesional los que, de alguna manera, aletargan la atención médica hacia pacientes que muchas veces llegan al hospital en situaciones límites, con un agravamiento de la afección que motiva la intervención médica. Las dificultades en la tramitación de la solicitud de turnos, las demoras que éstas acarrean hacen que, efectivamente, las personas de las comunidades terminen asistiendo al hospital en "casos extremos", cuando el deterioro es tal que amerita la "urgencia". Así, tales circunstancias son interpretadas por el personal médico aludiendo a que "el aborigen tiene un umbral alto para soportar el dolor", o bien a que "no se le ha inculcado un buen nivel de alarma"razón por la cual "llegan tarde", cuando el caso está muy avanzado-. De este modo, según esta perspectiva, la decisión acerca del momento de asistir al hospital recae nuevamente en dichos sectores poblacionales que no logran canalizar la asistencia médica pues les es atribuida poca o nula capacidad para discernir sobre la gravedad del caso y actuar en consecuencia, esto es, acudir al hospital.

En base a estas cuestiones reseñadas, a modo de cierre, me interesa dejar esbozado en qué sentido el "hacer vivir" de los procedimientos ligados a la atención de la salud son experimentadas por los indígenas asistidos como una forma encubierta de "dejar morir" (Foucault 2002).

\section{A modo de cierre}

Rastreando los mecanismos y condiciones que posibilitarían un acercamiento al hospital a los integrantes de las comunidades indígenas periurbanas, comencé a percatarme de ciertas situaciones claves que informaban sobre prácticas diferenciales. A través de ellas pude identificar la construcción del circuito de atención particular, asentado sobre una serie de mediaciones que aseguraban, con diferentes grados de éxito, la recepción de la demanda indígena.

Tales mediaciones tenían que ver con la puesta en marcha de procedimientos capaces de acreditar la necesidad de atención de la demanda en el hospital. Los procedimientos 
estaban ligados a la intervención de algún agente de salud que sirviera como "voz autorizada" para la presentación de la demanda. De este modo, la intervención podía adoptar diferentes modalidades, desde la necesidad de contar con los "papelitos" de derivación al hospital, o el involucramiento del agente sanitario local en casos de internación como nexo entre el paciente y el médico, hasta la designación y formación de un miembro de la comunidad para que actuase como "referente comunitario" en el hospital. Todas estas instancias daban cuenta de una serie de dispositivos donde se requería la mediación de algún agente de salud "reconocido" por el sistema que no sólo acreditara la "veracidad" de la demanda, sino que también le pudiera dar curso. En este sentido, para los miembros de la comunidad, el éxito de ser atendido dependía tanto de contar con el apoyo de algún agente de salud, como también de quién establecía el contacto -se tratase de un médico, un enfermero o de un "simple" agente sanitario. ${ }^{15} \mathrm{~A}$ diferencia de otros usuarios del sistema, para el indígena la capacidad de ser recepcionado en el hospital pasaba, entonces, por conseguir algún referente/efector de salud que pudiera representarlo en el servicio de atención.

De este modo, la activación del sistema de salud sólo a partir del "cuerpo sufriente o enfermo" (Fassin 2005) como el único recurso que otorga visibilidad a los indígenas, en un contexto donde sus vidas quedan bajo la disponibilidad de una supervivencia precarizada, dota de una dinámica particular a la asistencia allí dispensada. Las prácticas de reconocimiento social de existencia se reducen drásticamente a la atención médica y a la "adecuación" de los carriles que la harían posible. Siguiendo el planteo de Fassin, podemos decir que nos encontramos frente a una modalidad particular de gobierno de y por los cuerpos, fundada en una "bio-legitimidad", en la cual las decisiones políticas cotidianas se articulan en torno a la movilización del cuerpo alterado como único recurso a ser negociado en relación a la atención de la salud. ${ }^{16}$

En este sentido, la exposición del sufrimiento para la obtención de la asistencia en salud “apenas encaja en la manifestación de una reivindicación de derechos" (Fassin 2005, p. 212). Pues aunque los procedimientos de asistencia se enuncien tendientes a consagrar un derecho que les asiste tanto a criollos como indígenas, todo reclamo, petición o demanda que provenga de "las misiones" es visto por quienes trabajan en el sistema de salud como un exceso intolerable, pues ellas de alguna manera friccionan los límites pre-establecidos y ponen en cuestión la lógica de funcionamiento dispensada hacia ellas.

Es dentro de este marco que se asienta la desconfianza que los indígenas tienen respecto del sistema de salud formal. Al desgajar el estado de salud en que se encuentran las comunidades indígenas de sus condiciones de vida, las intervenciones socio-sanitarias quedan reducidas a garantizar un umbral de existencia precario y endeble. De acuerdo con esta lógica preponderante, sólo la supervivencia -en términos de garantizar "mínimos biológicos"- es la que se convierte en la justificación de la intervención, dejando intactas las condiciones causantes del deterioro de salud de la población indígena. De este modo, la necesidad de intervenir en lo que hace a la atención a la salud pasa, antes que por la integridad de la vida, meramente por el "cuerpo enfermo" (Fassin 2005) revelando una propensión compasiva. Así problematizada, la salud indígena refleja y traduce jerarquías implícitas de humanidad entre la población "solvente" blanca y la "no solvente" indígena. A través de los modos en que desde la gestión se concibe a la salud se va ejerciendo un control no sólo de la vida, sino también sobre el cómo de la vida, determinando quién merece vivir de determinada manera y tiene derecho a que ciertas condiciones de vida estén garantizadas. La atención a la salud entendida meramente 
como una cuestión de asistencia médica, y donde quedan bajo un cono sombra los condicionantes que afectan la vida de los indígenas, se inscribe entonces dentro de una forma de intervención que implica un modo particular de reconocimiento social fundado en la precarización absoluta de la condición humana. Aquí el cuerpo indígena reducido en términos de Necesidades Básicas Insatisfechas se convierte en objeto de intervención, estableciendo sólo como reivindicaciones legítimas aquellas que no se extralimiten de los contornos delineados según los circuitos de atención mencionados.

La lectura ideológica (Ricoeur 2001) acerca de la vulnerabilidad indígena en términos de "factores culturales", por parte de los agentes del sistema de salud formal, da cuenta de cómo los problemas sociales que atraviesan en la actualidad las comunidades indígenas son tamiza-dos y traducidos al lenguaje sanitario. Así, anudadas las intervenciones en el campo de la salud a las incidencias que tienen otras prácticas de distribución de recursos y espacios sociales, los indígenas perciben el accionar de los profesionales de la salud como prácticas que no hacen más que reforzar su lugar subordinado dentro las relaciones sociales allí entramadas. Desde esta perspectiva pueden interpretarse las reflexiones de un cacique wichí, que a raíz de explicarme el por qué "ahora estamos enfermos" y la relación con los servicios del sistema de salud, expresaba: “(...) es que el paisano molesta, nomás. Quieren hacer desaparecer al mataco (Wichí), ¿ha visto?; que seamos pocos, menos, así quieren hacer". Tal apreciación venía asociada a la lucha de su comunidad en relación a la extensión de los alambrados, fumigaciones de las fincas lindantes, a partir de lo cual me señalaba "nos están quitando vida totalmente. Nos estamos quedamos sin vida, porque nuestros alimentos ya no están por las empresas que están explotando los montes".

En este marco, los indígenas cargan con los estigmas de un orden social excluyente y de la segregación espacial que se expresan y quedan registrados en el deterioro físico de sus cuerpos. En dicho espacio social, el "cuerpo indígena" pasa a ser testigo que pone en evidencia procesos que necesitan ser ocultados a la luz de una zona que se proyecta como productiva, próspera y pujante. Nos encontramos, así, con los límites de un sentido sanitario hegemónico donde la vida indígena queda rebaja-da o reducida a las exigencias elementales del cuerpo -el hambre, el frío, la enfermedad (Fassin 2005, p. 211)- y la asistencia se circunscribe a una administración de "mínimos biológicos" en términos de satisfacción de "necesidades básicas" (Lorenzetti 2010, p. 215).

\section{BIBLIOGRAPHY}

Albó, X. (2004). Interculturalidad y salud. En G. Fernández Juarez (Coord.), Salud e interculturalidad en América Latina, Perspectivas antropológicas, (pp. 65-74). Quito: Abya- Yala.

Arrúe, W. y Kalinsky, B. (1991). De la “médica” y el terapeuta: la gestión intercultural de la salud en el sur de la provincia del Neuquén. Buenos Aires: Centro Editor de América Latina.

Boccara, G. (2004). Del buen gobierno en territorio Mapuche. Notas acerca de una experiencia en salud complementaria. Cuadernos de Antropología Social, (20), 113-129. 
Boccara, G. (2007). Etnogubernamentalidad: la formación del campo de la salud intercultural en Chile. Chungara, Revista de Antropología Chilena, 39 (2), 185-207.

Boccara, G. y Bolados, P. (2008). Gobernar a través de la participación. La fábrica del neoliberalismo multicultural en Chile. Memoria Americana. Cuadernos de Etnohistoria, 16 (2). Universidad de Buenos Aires.

Briones, C. (2005). Formaciones de alteridad: contextos globales, procesos nacionales y provinciales. En C. Briones (Comp.), Cartografías argentinas: políticas indígenas y formaciones provinciales de alteridad, (pp. 11-43). Buenos Aires: Antropofagia.

Buliubasich, C. y González, A. (Coords.) (2009). Los Pueblos Indígenas de la Provincia de Salta. La posesión y el dominio de sus tierras. Departamento San Martín. Salta: Universidad Nacional de Salta.

Carrasco, M. (2009). Tierras duras: Historias, organización y lucha por el territorio en el Chaco Argentino. Copenhague: IWGIA.

Cuyul, A. (2008). La Burocratización de la salud intercultural en Chile. Del Neo-asistencialismo al Autogobierno Mapuche en Chile [en línea]. [consulta: mayo de 2009]. <http:// www.mapuexpress.net/images/publica-tions/13_5_2008_17_18_49_1.pdf>.

Elias, N. (2000). Ensaio Teórico sobre as relacoes establecidos-outsiders. En N. Elias y J. L. Scotson, Os establecidos e os outsiders: sociologia das relacoes de poder a partir de uma pequena comunidade, (pp. 19-50). Río de Janeiro: Jorge Zahar ed. (Trabajo original publicado en 1976)

Deleuze, G. (1999). ¿Qué es un dispositivo?”. En E. Balbier, G. Deleuze, H. L. Dreyfus, M. Frank, A. Glücksmann y G. Lebrun (Eds.), Michel Foucault, Filosofo, (pp. 155-163). Barcelona: Gedisa.

Fassin, D. (2004). Entre las políticas de lo viviente y las políticas de la vida: hacia una antropología de la salud. Revista Colombiana de Antropología, 40, 238-318.

Fassin, D. (2005). Gobernar por los cuerpos, políticas de reconocimiento hacia los pobres y los inmigrantes. Educaçâ, XXVIII (056), Pontifícia Universidade Católica Do Río Grande Do Sul, Porto Alegre, 201-226. [en línea]. [consulta: agosto de 2008]. <http://redalyc.ua-emex.mx/redalyc/ pdf/848/84805604.pdf>.

Fassin, D. (2008). El hacer de la Salud Pública. [en línea]. [consulta: octubre de 2009]. <http:// www.equidad.cl/bi-blioteca/formador-de-formadores/modulo-1/El\%20 hacer\%20de\%20la\% 20salud\%20p\%C3\%BAblica\%20 Didier\%20Fassin.pdf>.

Fernández Juarez, G. (Coord.) (2006). Salud e interculturalidad en América Latina. Antropología de la salud y crítica intercultural. Quito: Abya-Yala.

Foucault, M. (1985). "El juego de Michel Foucault”, entrevista publicada en la revista Ornicar, $\mathrm{N}^{\circ}$ 10, 1977. En M. Foucault, Saber y verdad, (pp. 127-162), Madrid: Ediciones de la Piqueta.

Foucault, M. (2002). Historia de la Sexualidad, Tomo I La voluntad de saber. Buenos Aires: Siglo XXI Editores Argentina. (Trabajo original publicado en 1976)

García Vázquez, C. (Comp.) (2009). Hegemonía e Interculturalidad. Poblaciones originarias y migrantes: la interculturalidad como uno de los desafíos del siglo XXI. Buenos Aires: Prometeo Libros.

Gordillo, G. (1998). Terror en el Pilcomayo: fragmentos de historias olvidadas (1885-1937). Nosotros los Otros, (3), Año II, Septiembre 1998. Buenos Aires, 7-11.

Gordillo, Gastón (2006). En el Gran Chaco: antropologías e historias. Buenos Aires: Prometeo. Gordillo, G. y Leguizamón, J. M. (2002). El río y la frontera: movilizaciones aborígenes, obras públicas y Mercosur en el Pilcomayo. Buenos Aires: Biblos. 
Lorenzetti, M. (2010). Salud intercultural: articulaciones entre biopolítica y alteridad en las intervenciones socio--sanitarias para indígenas. Tesis Doctoral, Universidad de Buenos Aires (UBA), Facultad de Filosofía y Letras, Argentina.

Menéndez, E. (2001). Biologización y racismo en la vida cotidiana. Alteridades, 11 (21), México, 5-39.

Ramírez Hita, S. (2009). Calidad de atención en salud: prácticas y representaciones sociales en las poblaciones quechua y aymará del altiplano boliviano. La Paz: OPS/OMS.

Ricoeur, P. (2001). Conferencia introductoria. En G. Taylor (Comp.), Ideología y Utopía, (pp.45-65), Barcelona: Gedisa.

Segato, R. (2007). La nación y sus otros: raza, etnicidad y diversidad religiosa en tiempos de políticas de identidad. Buenos Aires: Prometeo Libros.

Tamagno, L. (Coord.) (2009). Pueblos indígenas: interculturalidad, colonialidad, política. Buenos Aires: Biblos.

Trinchero, H. H. (2000). Los dominios del demonio: Civilización y Barbarie en las fronteras de la Nación, El Chaco Central. Buenos Aires: EUDEBA.

Trinchero, H. H. (2007). Aromas de lo exótico (retornos del objeto): para una crítica del objeto antropológico y sus modos de producción. Buenos Aires: SB.

\section{Fuentes periodísticas}

Según Urtubey, los aborígenes no van al hospital por razones culturales. (2011, febrero 5). Radio salta.com [en línea]. [consulta: febrero de 2011]. <http://www. radiosalta.com/

detalle_noticias.php?id_contenidos=1031>.

Según Urtubey, los aborígenes desnutridos no van al hospital “por una cuestión cultural”. (2011, febrero 9). La Política Online [en línea]. [consulta: febrero de 2011]. <http://

www.lapoliticaonline.com/noticias/ val/71200-6/segun-urtubey-los-aborigenes-desnutri-dos-novan-al-hospital-\%E2\%80\%9

\section{NOTES}

1. Entre los programas específicos diseñados desde el Ministerio de Salud de la Nación se implementaron: el Programa de Apoyo Nacional de Acciones Humanitarias para Poblaciones Indígenas (ANAHI), el sub-programa Equipos Comunitarios para Pueblos Originarios y el Marco de Planificación para Pueblos Indígenas en el Proyecto de Funciones Esenciales y Programas Priorizados de la Salud Pública (FESP). A través del Programa ANAHI, fue creada una red de agentes sanitarios indígenas que se incorporaron al primer nivel de atención de salud en calidad de "facilitadores culturales". Con el Programa Equipos Comunitarios se conformaron equipos interdisciplinarios, capacitados en Salud Intercultural y Comunitaria, para el trabajo en zonas geográficas con población indígena. Mediante el FESP se confeccionaron Planes Provinciales Indígenas para extender a las comunidades indígenas ciertos programas de promoción de la salud y prevención de las enfermedades, en especial aquellos abocados a la prevención de enfermedades crónicas.

2. En este sentido, la "interculturalidad" como paradigma de gestión ha dado lugar a la configuración y re-creación de las diferencias mediante nuevas formas de ponderación, sustentadas en relaciones interétnicas específicas y dentro de contextos socio-históricos particulares. En tanto modalidad constructora de diferencias, la interculturalidad, no se 
desprende de un objeto preexistente (Pueblos Indígenas), sino que se configura y se modifica de acuerdo con los regímenes de visibilidad que la constituyen y en los cuales emerge dicho objeto. De este modo, la interculturalidad como dispositivo de intervención ha re-significado y reorganizado los marcos interpretativos y prácticas que diagraman las políticas públicas dirigidas al colectivo indígena (Lorenzetti 2010, pp. 16-17). De acuerdo a esta perspectiva, entonces, la "interculturalidad" se entiende como una forma de procesar las diferencias inscriptas en una racionalidad política que va conformando y dando espesor a un dominio práctico que se instituye como experiencia.

3. En el Departamento de San Martín de acuerdo a los datos censales del año 2001 la cantidad de hogares con indígenas es de 4.418, lo que equivale al 28, $8 \%$ del total provincial (Buliubasich y González 2009). Dicha jurisdicción integra la región biogeográfica conocida como el Gran Chaco, "una planicie de cerca de un millón de kilómetros cuadrados que ocupa partes de Bolivia, Paraguay, Brasil y Argentina" (Carrasco 2009, p. 67) El Chaco Salteño forma parte del denominado Chaco Central que corresponde al espacio territorial ubicado entre los dos ríos principales de la región: el Pilcomayo y el Bermejo. Allí viven numerosas comunidades pertenecientes a distintos Pueblos Indígenas: Ava Guaraní, Chané, Chorote, Chulupi, Tapiete, Toba, Wichí.

4. Entre tales procesos significativos podemos mencionar los diferentes frentes colonizadores implicados en la expansión de la "frontera interna" y la valorización del territorio ocupado por indígenas a través de los cuales se fue construyendo una imagen del Chaco Salteño como lugar inhóspito, marginal, pero al mismo tiempo rico y próspero (Trinchero 2000 y 2007). Tres frentes militar, religioso y económicos (obrajes madereros, ingenios azucareros, "criollos pioneros" ganaderos)- fueron abriéndose paso, incursionando en lo que se ha dado en llamar la "conquista pacífica" (Gordillo 1998).

5. Domingo Astrada fue quien dirigió la expedición en el año 1902 de los criollos ganaderos que incursionaron en el Chaco Salteño. La ocupación y asentamiento de ganaderos provenientes de las provincias limítrofes se dio luego de que él mismo recibiera la autorización de las autoridades nacionales. La expedición se justificaba en términos de gesta patriótica y en este sentido quienes la llevaron a cabo son re-conocidos como "los pioneros" en adentrarse en el denominado "desierto verde" (Trinchero 2000, pp. 220-231).

6. Con el término "misión", a nivel local se hace referencia a las comunidades indígenas de la zona. Tal denominación y su respectiva connotación viene ligada al proceso de creación de misiones llevado a cabo por las iglesias de procedencia Anglicana, Pentecostal y Católica iniciado a principios del siglo XX en la región del Chaco Central. El proceso de misionalización respondía, entre otras cuestiones, a lograr la sedentarización de los grupos cazadores-recolectores, disciplinándolos como mano de obra a ser incorporada en los ingenios azucareros y los obrajes madereros (Trinchero 2000; Carrasco 2009).

7. Comúnmente, quienes allí trabajan con población indígena utilizan la palabra "misión" en un doble sentido, pues si bien es frecuente que señalen "estoy trabajando en Misión” para indicar que están desempeñando sus tareas en una comunidad indígena, también suelen sustituir dicha frase con "tengo la Misión", enfatizando de esta manera el rol que le cabe dentro de dicho espacio.

8. Basta para ello recorrer las notas periodísticas publicadas durante las inundaciones del diciembre de 2005 en Tartagal; el temporal del verano, agravado en abril de 2006 que no sólo dejó incomunicada la ciudad de Tartagal, sino también provocó desmoronamientos de viviendas en la ribera de dicho río; asimismo las notas sobre los desbordes de los ríos Pilcomayo, Bermejo y Caraparí en los meses de Enero y Marzo de 2008, y por último el alud de agua y barro producido en febrero de 2009 que afectó a los barrios aledaños al río Tartagal, a la comunidad Toba y a parte de la comunidad Guaraní Cherenta. En este último caso, las opiniones de funcionarios abocados a entender lo que pasó en términos de "obra de la naturaleza" desligando lo sucedido a toda actividad del hombre (desmonte, trabajos de prospección de hidrocarburos) encontraron la con- 
testación de los propios damnificados y organizaciones ambientalistas que no tardaron en replicar señalando que los troncos bajados del cerro en su mayoría "venían sin raíces" (Lorenzetti 2010, p. 93).

9. Me interesa resaltar el tipo de adjetivación que se hace de la pobreza al atribuirle un carácter "endémico", al igual que se lo hace con las enfermedades destinadas a perpetuarse. El carácter endémico asociado a la pobreza parece venir a reforzar una idea de pobreza como enfermedad y una idea de enfermedad "impermeable" a las acciones implementadas.

10. Si hasta la década de 1960 los frentes productivos donde se insertaban los indígenas eran los ingenios azucareros y el cultivo comercial de algodón (Gordillo 2006; Trinchero 2000 y 2007; Gordillo y Leguizamón 2002), a partir de la década del 70 la inserción de los indígenas al mercado laboral cambiará notablemente, acotándose sustancialmente los medios y recursos posibles para la manutención de las familias.

11. Como señala el informe entre el año 2006-2007, realizado por la Secretaría de Derechos Humanos de la Nación y la Universidad Nacional de Salta, en el departamento de San Martín: “los recursos para la subsistencia de las familias indígenas provienen en gran medida de trabajos asociados a un contexto de mayor interacción con el medio urbano, y a un mercado laboral inestable en fincas" (Buliubasich y González 2009, p. 55). El caso de los "servicios" -ítem que consigna lo que regionalmente se denomina "changas", se trata de una prestación circunstancial a cambio de una paga inmediata, como por ejemplo, cortar el pasto, limpiar un fondo, etc.- se ubica en primer lugar, quedando en cuarto lugar los "empleos temporarios". El hecho de que los "servicios" se ubiquen en primera escala no debe inducir a pensar que sea la única actividad que realizan. La actividad demuestra sólo mayor frecuencia, pero no implica de ningún modo que sea el sostén económico primordial. Entre las actividades tradicionales de subsistencia se destacan las prácticas de cultivo. La mayor presencia de actividades de cultivo en relación a las prácticas de caza y recolección puede deberse a que estás últimas requieren de un franco acceso al monte y un medio no degradado, situación que les está siendo impedida a partir de las últimas décadas (Buliubasich y González 2009, p. 55).

12. Las expresiones entrecomilladas fueron recogidas durante mi trabajo de campo en la zona, cuando a raíz de los reclamos indígenas canalizados a través de los cortes de las rutas 34 y 86 , distintas personas manifestaban sus opiniones sobre el tema, resaltando los inconvenientes que traían aparejados los cortes en relación a la "libre circulación" y perjuicios que los mismos ocasionaban para "sacar a la zona para adelante".

13. Los agentes sanitarios trabajan en los equipos de APS realizando las tareas de promoción de la salud y prevención de las enfermedades mediante las visitas domiciliarias a las familias que integran un sector.

14. En cierto sentido, para los distintos servicios del hospital, la mediación realizada por los agentes sanitarios "cercanos" a las comunidades se convierte tanto en una posibilidad de controlar las demandas indígenas, como de disciplinar el trabajo de los primeros. Se establece entonces un doble control, hacia afuera en las comunidades, pero también hacia adentro, sobre lo que constituye el primer eslabón del sistema: la Atención Primaria de la Salud.

15. La rapidez en la respuesta a la solicitud presentada era más inmediata si la efectuaba un médico que si intervenía un enfermero o un agente sanitario, dan-do cuenta de la posición jerárquica dentro de la estructura hospitalaria.

16. Con el neologismo "biolegitimidad", Fassin hace referencia a las formas contemporáneas de politización de la vida, en las que el "cuerpo expuesto" -ante la administración del Estado- en términos de una biologización de las necesidades humanas, constituye la última ratio capaz de impulsar algún tipo de intervención. 


\section{ABSTRACTS}

In this paper I examine in what terms the health conditions of indigenous communities in the department of San Martín (Salta, Argentina), are problematized within the health sector. Specifically I examine how, and by which itineraries, indigenous become visible within the hospital structure, considering the medical and care circuits based on the concept of "cultural adequacy". Analysing these socio-health initiatives it is possible to understand in what sense the "let it live" principle raised by the public health system is in fact experienced by the natives assisted as a disguised form of "leting them die". Reconstructing the relations at stake and their conditioning factors, the analysis here presented enables the understanding of the frictions arisen when the right to health is hegemonically reduced to the access to medical care.

En este trabajo analizo en qué términos se problematizan, desde el ámbito sanitario, las condiciones de salud de las comunidades indígenas periurbanas del departamento de San Martín (Salta, Argentina). Puntualmente examino cómo, y a través de qué itinerarios, los indígenas se vuelven visibles dentro de la estructura hospitalaria, atendiendo a los circuitos de atención médico-asistenciales sustentados en lo que se propone como "adecuación cultural". A través de un análisis situado de las iniciativas socio-sanitarias es posible entender en qué sentido el "hacer vivir" planteado desde el sistema público de salud es experimentado por los indígenas asistidos como una forma encubierta de "dejar morir". Es a partir de re-construir la trama de relaciones en juego y sus condicionantes que pueden hacerse inteligibles las fricciones que suscita el planteo del derecho a la salud cuando queda reducido, hegemónicamente, sólo al acceso de la atención médica.

\section{INDEX}

Palabras claves: relaciones interétnicas, salud indígena, Chaco Salteño

Keywords: inter-ethnic relations, indigenous health, Chaco Salteño.

\section{AUTHOR}

\section{MARIANA LORENZETTI}

Instituto de Ciencias Antropológicas, Sección de Etnología, Facultad de Filosofía y Letras, Universidad de Buenos Aires. Becaria Postdoctoral del Consejo Nacional de Investigaciones Científicas y Técnicas (CONICET), Argentina.

Correo electrónico: lorenzettimariana@gmail.com 